\title{
SOME THINGS A DENTAL PRACTITIONER SHOULD KNOW ABOUT ORTHODONTIA TO BEST SERVE HIS PATIENTS*
}

\author{
By. C. Angus Kennedy, Toronto, Canada
}

\begin{abstract}
A S THE heading of this paper signifies, this will be a talk with the general practitioner who lives in a eity where he has the opportunity of conversing and consulting with an orthodontist.

There have been so few chances for him to receive any instruction in this subject, on account of so few essays appearing in our magazines, or such topics being so seldom on the programme of any of our dental society conventions.

The first step in this line would be to take care of the health of the patient and see that his nervous system would be able to stand the duration of treatment. As some cases are long, the history of health should be thorough, and, where necessary, advice given to the patient and parent.

The practitioner should have a knowledge of the development and growth of the tooth, the alveolar process, and pericemental membrane, the characteristies and functions of the bone cells in tearing down and rebuilding of bone and tissue, the development and normal use of the muscles of the face and jaws, the disuse and abuse of these same muscles and the resulting malocclusion. These results are often the cause of the growth of adenoids and nasal obstructions, which in turn cause mouth-breathing. Through lack of proper instructions, the child is allowed to continue in this practice, producing a great malocclusion, facial deformity, and pathologic conditions of the respiratory tract.
\end{abstract}

We see these patients from afar,-thin, sallow cheeks, undeveloped upper lip, protruding upper anterior teeth, narrow-chested, and a general appearance of being poorly nourished. These symptoms belong to the mouth-breathing habit, and are started by the patient not being able to breathe through the nose on account of adenoids or nasal obstructions.

The respiratory tract should be examined and treated by a rhinologist to elear the passages. After this has been accomplished, the lips should be held together at night by adhesive tape, or some such appliance, until the habit is broken and the patient is breathing in a normal manner.

Another habit is that of tongue biting or finger sucking, which is very hard to overcome, and which produces an infraocclusion, the patient being unable to bite anything with the anterior teeth.

By studying the eruptive period of the temporary and permanent teeth, the general practitioner should know when to extract and when not to extract. In deciding this point he should be sure of his diagnosis and also be able to give a good prognosis of the case. The extraction of temporary teeth

* Read before the Alumni Society of the Dewey School of Orthodontia, Atlantic City, N. J., April 25 and 26,1921 
too early will allow the remaining teeth to drift, elosing the space for the permanent teeth following. Also, the extraction of the first permanent molar is a dangerous operation, as it allows the second molar to tilt forward, causing the inclined planes to occlude in a mesial position, and forcing the opposing jaw into malocclusion. In fact, the extraction of teeth for the correction of malocclusion should be studied very carefully, as a couple of years afterwards a much greater deformity may take place as a result of the extraction.

A thorough knowledge of the causes of the promotion and delaying of eruption of the teeth, such as syphilis, rachitis, tuberculosis, is also very necessary.

In speaking on this subject it should be impressed upon all practitioners that we should have a good idea of what correct occlusion is, and what it stands for, as malocclusion is only recognizable as being away from normal occlusion. This is one of the first requisites for giving a good diagnosis, and we cannot give proper treatment without the knowledge of the fundamental principles. It is absolutely imperative that we be able to correctly diagnose malocclusion before we can hope to successfully treat it. It is necessary to know the relationship of every tooth, eusp, and inclined plane of the teeth of the mandible to the teeth of the maxillæ.

Malocclusion of the teeth is not inherited. The child inherits characteristics from the parent, but the influence on malocclusion is limited to the environment of the child, whether it be in its embryonic state or after birth.

Under modern methods of living, a very large percentage of babies are bottle-fed. Aside entirely from the vital necessity for the baby's food being so prepared as to contain a "balanced diet" during this important period, it is essential that the child find it necessary to thoroughly exercise the jaws at the time of feeding.

The baby should be held in the arms in the posture as for breast-feeding and the bottle so held that the child is compelled to work for the food. A most pernicious habit is that followed in many cases where the bottle is propped up and a nipple used permitting such free flow of food that practically no effort is required on the part of the child to obtain the food.

Food and exercise are the most important elements in the proper development of the dental arches, and my plea is that the advantages of thorough mastication be not overlooked, even in the case of the very youngest child.

One should have a good working knowledge of the above events in the life of a child, to be able to give a good diagnosis and information to the parents. A physician, in being called to the bedside, gives a thorough examination and diagnosis of the symptoms as he sees them, and gives his patient the result of his deliberations. This advice might be for consultation with a surgeon or specialist, or for an operation. The result is that the patient is receiving the best advice and services which are possible. Our consultations should take place early in the life of the child, so that the orthodontist would not have to wait until the permanent teeth are all in position before starting a difficult case. The orthodontist needs the hearty cooperation of the practitioner all the time, and if we could work in closer touch and together, 
the patients would all be benefited: An example of this was brought to my attention a few weeks ago, when one of our best practitioners had inserted an inlay in a premolar for a patient who was also under the care of an orthodontist. He thought he had a very good result in the inlay. The grooves and marginal ridges were in good condition, and he had splendid oeclusion. The orthodontist said that the mesio-distal diameter of the reconstructed tooth was not wide enough, and that the inlay should be $3 / 100$ of an inch longer, so as to keep the correct occlusal line.

The consultation which afterwards took place between the practitioner and the specialist was very beneficial to both, as each saw the oral cavity from the viewpoint of the other, and the result has been an education and a great help to both,--the specialist pointing out the phases where his difficult work can be assisted by the practitioner, especially in the case of extractions; carving cusps for fllings and inlays, and permanent restorations for retaining appliances, and the practitioner explaining his features of the case.

If we, as a profession, are going to render the greatest possible service to the public, there must be closer cooperation between the dentist and the orthodontist. There are many difficulties which we have to overcome, and by working together the patient is bound to benefit, and the oral cavity of the child will be set in a healthy and normal condition. Often, we who are spending all our time in trying to get efficient results have some hard problems to solve, when a consultation would help materially.

There has been a tendency in the past for the two branches of dentistry to drift apart, instead of combining their efforts.

There is a great field for the general practitioner in the new department of preventive orthodontia. He comes in contact with the child before the orthodontist, and could prevent numerous cases from developing into severe cases of malocclusion.

He should know occlusion and be able to recognize irregularities in a developing mouth; also, that the time to correct any malocclusion is as soon as the tendency manifests itself, not waiting until the patient is older, or until all the permanent teeth are in position. The case should be completed by that time, instead of just beginning.

When a young patient is found to be a mouth-breather, he should look for the cause along the respiratory tract; or when a temporary tooth is remaining in position too long, and thereby causing the permanent teeth to erupt in a malposed position; or when a child is not developing the normal spaces between the anterior teeth, showing that the jaw is not expanding and nature is making no preparation for the reception of the larger permanent teeth; if he would send the patient for a consultation with an orthodontist, their combined judgment would result in better service to the patient.

It takes a long time and special study to properly diagnose and pass judgment on the treatment of malocclusion and the dentist often overlooks conditions today that tomorrow may prove to be most serious deformities.

Dr. F. B. Noyes says: "It should be the dentist who would send patients to seek the services of the orthodontist, and if the dentists were alive to 
their responsibility, and were sufficiently informed to recognize the existence of malocclusion before it developed into deformity, it would be better for all concerned."

In conclusion I would say that the closer the relation concerning consultation between the dentist and the orthodontist, the better it will be for the dental profession and the general public.

\section{DISCUSSION}

Dr. H. B. Hamilton, Ithaca, N. $Y$.- I do not know that I can ard anything of partic. ular interest to this excellent paper, because I agree heartily with most of the things the author has said. There is one thing, however, I might lay a little stress upon, and that is that the average dentist does not seem to appreciate normal occlusion or normal tooth forms. One of the most common troubles we have to contend with is the poorly shaped occlusal res. torations. The average occlusal filling or inlay is flat and destitute of fissures and grooves, and this type of work seems to be more or less general, judging from what $I$ see in the mouths from many parts of the country. It is my practice to reshape these restorations with a bur to some semblance of normal form.

It seems to me that if the general practitioner gives any attention whatever to orthodontia, he will very soon appreciate the necessity of normal tooth form and his restorations will improve wonderfully, both to his own and his patients' adrantage.

Dr. Joseph D. Eby, New York City. - I have enjoyed the Doctor's paper very much and am glad that our Committee had the foresight to incorporate this subject into our program for several reasons:

This is always a timely subject, for it is impossible for specialists to regard too kcenly, or have their attention called too frequently to the great obligations they are under to general practitioners and specialists in other services.

It is my opinion that alas too few of us have meditated over this subject and given it the study which it merits and accordingly adopt a definite policy toward fellow-men in order to overcome our various short-comings in traits of character and temperament as we should in relation to this topie.

The relation between the specialist in a given field and the general practitioner is one which must be handled in a very careful and tactful manner and which, if analyzed, becomes a recognition of mutual intelligence, wherein the minds must be brought togetler from divergent thoughts, which time under different duties naturally effects, to an equal basis or conmon meeting ground, in order to best serve their patients.

As soon as one man assumes the attitude that lie knows so much more than the other fellow, that moment he begins to show his own self-centered disregard and begins to develop self-destruetive conditions which, upon becoming his repute, are dearly paid for, as the selfplaced halo over the high brow eventually becoming a millstone around the neck.

There is also the opposite extreme to this attitude which reflects self-centeredness and becomes so objectionable to some men that their attention is only fretted instead of attracterl, that is, the attitude of such simple simplicity, such as would better suit a layman in discourse on the subject.

I do not think that any of ns like to be led to feel that we are or should be freshmen students again; it is very easy to broach the practitioner's feelings in this way, thereby exchanging difficulties for the purposes sought.

There is no law which defines orthodontists; legally we are dentists and our relations with practitioners should be from the viewpoint of dentists, not srparatex by sone mystic portal beyond which orthodontists thrive in another atmosphere.

The thought which I am endeavoring to express may be perhaps better illustrated by deseribing a happening which came under my observation and being partially instrumental was much to my embarrassment.

Once an orthodontist of great reputation travelled a long distance to take some thoughts 
on orthodontia to a meeting of a large body of general practitioners who had gathered from several states to hear him.

His interpretation of that situation was to expound the highest theories and most tedious teehnic which are the very reasons why orthodontia is a specialty and is prohibitive in that sense in general practice.

His mission was lost with the wonderful opportunity he had to do great good, because of his failure to realize that those dentists were hungry for more of the fundamentals with which they could serve humanity better by knowing how and when to cooperate with orthodontists or in the treatment of some simple conditions, and he left them worse confused than when he met them, with a bad attitude established toward himself and discouragement toward orthodontia, when as a matter of fact their work is more important to us than our work is to them.

If orthodontists will meet their fellow professional brethren as equally highly trained technicians in other practice, carry the proper message to them, and deal with them in the plain matters of fact, compatible with a generous mixture of the Golden Rule, then and then only will the flavor be pleasant and become the asset of each individual's usefulness and a credit to the cause to which each one devotes his life's work.

I trust that what I have said is entirely consistent with Dr. Kennedy's thoughts as I would hate to be guilty of departing from the essence of this too important phase of our work which makes and breaks so many men.

I wish to thank friend Kennedy for bringing the thoughts in this able essay to us and also trust that copies of it may fall into our hands during the quiet hours, when after reading it again, we may inventory ourselves to the fullest extent of our personal needs along these lines.

Dr. Frank A. Delabarre, Boston, Mass.-I would like to speak on this topie in particular because I was a general practitioner before I took up the specialty of orthodontia, so I feel peeuliarly kindly towards both classes of men, knowing intimately the problems that confront them.

There is one point I would in particular emphasize as being the one way in which the general practitioner of dentistry can help the orthodontist most. That one way is through an adequate appreciation of the fact that it is absolutely essential to preserve the temporary teeth in health throughout their intended life. And why For the most obvious reason that in all cases of malocclusion that we come across neglect of the temporary teeth seems frequent and most severe, complicating the things with which we have to deal. If we could have our cases of malocelusion come to us without the complications that ereep in through neglect of the temporary teeth, through their decay, through their being abscessed, and to early loss, our eases of malocclusion would be much simpler to handle. In that way alone the dental practitioner could help us to the greatest extent.

Dr. C. R. Baker, Evanston, Illinois.-I agree thoroughly with all that was expressed in the paper and also in the diseussion. There is one idea that $I$ might add and that is, when deciduous teeth are lost prematurely, the general practitioner should see that the normal space is maintained in the arehes. An efficient appliance should be placed by the dentist or by an orthodontist. In case a deciduous molar is lost prematurely, the space maintained should be the mesio-distal width of the deciduous molar rather than the mesio-distal width of the corresponding premolar.

Dr. John A. McPhail, Cincinnati, Ohio.-I think we have made a mistake because we have our cabinets filled with malocclusions. I believe the average general practitioner does not understand normal occlusion and the eare of the deciduous teeth.

In attending any dental meeting you hear a great deal about the ocelusion of teeth, and it seems peculiar to me that a man who can get the teeth in normal ocelusion cannot recognize a malocelusion in a deciduous set of teeth. That is one place where we make a mistake. Everything is malocelnsion with us. I have a boy of 6 , and I am unfortunate in having another child who has only normal occlusion on one side. He has a perfect set of teeth on one side with normal occlusion. I have taken impressions of their teeth and have been making models, and when a ease comes in I get out these cases of normal occlusion. In 
my boy the occlusion is not quite normal. He is one of those borderline cases. I show the little patients what a normal occlusion is, what a normal arch is, as $I$ can understand it. It seems to me, it ought to be embarrassing to a general practitioner to have a mother or one of the parents call attention to a malocclusion when he las bcen working for the child for years. It would be embarrassing to me $I$ am sure. Those who are engaged in general practice must have a great many eases of malocelusion in their praetice. There is a tendency for all of us to see in the mouth the things for which we are looking. If you are a pyorrhea specialist, and a patient comes to you, you will see pyorrhea. You may want the teeth that are involved taken out. On the other hand, the bridge man wants to put in a bridge. I think all the average orthodontist ean see is malocelusion. It seems to me, we should view the mouth as a whole. It would be a good thing for us to see the mouth ontside of malocelusions once in a while and to remember that there are other things in the mouth besides deformities. We can be of great help to the general practitioner in this way as well as be of profit to ourselves.

I have tried to cooperate with men who send me eases. I like to send back a patient to a dentist who referred the case to me after the appliances are on to see whether he agrees with me as to how the bands ought to be put on, and later I send the patient back to him to see whether $I$ an keeping the teeth in proper shape and in regard to the general condition of the mouth. It is up to us, I think to cooperate with the general practitioner rather than set ourselves apart as somebody who is wiser than the rest, because the chanees are we are not very much different.

Another thing: Dr. Dewey had an editorial some time ago about extracting teeth. I had a little patient come to me recently who was sent to have some teeth extracted in order to make room for the laterals; with the instruction that if we took out the temporary cuspids it would make room for the laterals. We all know that it would, but how much trouble we would get in later on. An exodontist said that was not the right thing to do, but if the general practitioner wants to have it done, I will do it. It is unfortunate that our consciences can be made so blunt that we are influenced to do these things even though we know they are wrong. I believe when an exodontist will extract the teeth of a patient when it is not indicated, we have a right to censure him and tell the patient he was wrong. I do not think we need to use any diplomacy about that, because the patient ought to know. If the exodontist extracted the teeth through ignorance, it is a different proposition.

Dr. C. A. Kennedy, Toronto, Canada (closing). - I want to thank the members for thèir liberal and free discussion. If we could take a referred patient to the practitioner and explain what we purpose doing and show him some of our difficulties, we would gain his cooperation much more sympathetically. Our speeialty needs this, and we should strive at all times to gain it. 